\title{
Clinical significance of high expression of miR-452-5p in lung squamous cell carcinoma
}

\author{
XIAO-NING GAN ${ }^{1 *}$, TING-QING GAN ${ }^{2 *}$, RONG-QUAN HE ${ }^{2}$, JIE LUO $^{2}$, RUI-XUE TANG ${ }^{1}$, \\ HAN-LIN WANG ${ }^{1}$, HONG ZHOU ${ }^{1}$, HUI QING ${ }^{1}$, JIE MA ${ }^{2}$, XIAO-HUA HU ${ }^{2}$ and GANG CHEN ${ }^{1}$ \\ Departments of ${ }^{1}$ Pathology and ${ }^{2}$ Medical Oncology, First Affiliated Hospital of Guangxi Medical University, \\ Nanning, Guangxi Zhuang Autonomous Region 530021, P.R. China
}

Received January 23, 2017; Accepted January 26, 2018

DOI: $10.3892 / \mathrm{ol} .2018 .8088$

\begin{abstract}
The role of microRNA (miRNA)-452-5p in lung squamous cell carcinoma (LUSC) remains unclear. Therefore, the present systematic study was performed to investigate the clinical significance and the rudimentary mechanism of the function of miR-452-5p in LUSC. The Cancer Genome Atlas (TCGA) and Gene Expression Omnibus (GEO) databases were utilized to confirm the expression level and clinical value of miR-452-5p in LUSC. Using online databases and bioinformatic software, gene ontology $(\mathrm{GO})$, pathway and protein-protein interaction (PPI) analyses of miR-452-5p target genes were performed to examine the molecular mechanism of miR-452-5p. The association between the expression of miR-452-5p and that of its hub genes was verified using TCGA. Based on TCGA data on 387 clinical specimens, the expression of miR-452-5p in LUSC was significantly increased compared with adjacent lung tissues (7.1525 \pm 1.39063 vs. $6.0885 \pm 0.35298 ; \mathrm{P}<0.001)$. The expression levels of miR-452-5p were significantly correlated with age $(\mathrm{P}=0.001)$ and tumor-node metastasis stage $(\mathrm{P}=0.028)$. Furthermore, the increased expression of miR-452-5p in LUSC compared with non-cancerous tissue [standard mean deviation (SMD), 0.372;
\end{abstract}

Correspondence to: Professor Gang Chen, Department of Pathology, First Affiliated Hospital of Guangxi Medical University, 6 Shuangyong Road, Nanning, Guangxi Zhuang Autonomous Region 530021, P.R. China

E-mail: chen_gang_triones@163.com

Professor Xiao-Hua Hu, Department of Medical Oncology, First Affiliated Hospital of Guangxi Medical University, 6 Shuangyong Road, Nanning, Guangxi Zhuang Autonomous Region 530021, P.R. China

E-mail: gxmuhxh@163.com

*Contributed equally

Key words: lung squamous cell carcinoma, microRNA-452-5p, cyclin dependent kinase inhibitor 1B, The Cancer Genome Atlas, Gene Expression Omnibus, clinicopathological parameter
95\% confidence interval $(\mathrm{CI}), 0.020-0.724 ; \mathrm{z}=2.07 ; \mathrm{P}=0.038]$ was validated by a meta-analysis of 720 clinical samples. The GO and pathway analyses revealed that miR-452-5p target genes were mainly enriched in the 'regulation of transcription', 'nucleoplasm', 'protein binding' and 'cell cycle' pathways. A total of 10 hub genes were identified by PPI analysis, and 5 hub genes (SMAD4, SMAD2, CDKN1B, YWHAE and YWHAB) were significantly enriched in the 'cell cycle' pathway. The expression of CDKN1B was negatively correlated with miR-452-5p $(\mathrm{P}=0.003)$. It was concluded that miR-452-5p may serve an essential role in the occurrence and progression of LUSC by targeting CDKN1B, which is involved in the cell cycle.

\section{Introduction}

The incidence and mortality rates of lung cancer are the highest among all types of malignant neoplasm in China and worldwide (1-3). Lung cancer can be divided into two histological categories: Non-small cell lung cancer (NSCLC) and small cell lung cancer (SCLC). NSCLC accounts for $~ 80 \%$ of lung cancer cases, including lung adenocarcinoma (LUAD), lung squamous cell carcinoma (LUSC) and lung large cell carcinoma (LULC) (4,5). Although the incidence of LUSC can be prevented to some extent by regulating tobacco smoking (6), the mechanism of tumorigenesis and progression of LUSC remains poorly characterized. There has been great progress in molecular targeted therapies for LUSC (7-9). However, resistance to targeted drugs remains high, and the proportion of responsive patients is limited. Therefore, the development of novel diagnostic and therapeutic tools for LUSC is of great importance.

microRNA (miRNA) is a class of endogenous non-coding RNA molecules, which are 22 nucleotides in length and regulate protein translation $(10,11)$. Previous studies have demonstrated that miRNAs silence genes by inhibiting the synthesis of associated proteins or degrading the mRNA of target genes, and therefore serve an important role in the regulation of growth, proliferation, differentiation, apoptosis and development of cancer (12-14). Numerous studies have reported the role of miRNA in the progression of LUSC and its value in the diagnosis, treatment and prognosis of this disorder (15-18). 
miR-452-5p (previously named miR-452) is obtained by modification of the $5^{\prime}$ end of pre-miR-452 $(19,20)$. Previous studies have reported that miR-452-5p expression in different types of cancer is distinct, where its expression is upregulated in urinary tract epithelial tumors, esophageal cancer and liver cancer (21-23) but downregulated in breast cancer, prostate cancer and glioma (24-26). Zhang et al (27) and He et al $(28,29)$ reported low expression of miR-452-5p in NSCLC cells and tissues, respectively. However, these studies were limited by the quality of the LUSC samples used. Therefore, the expression level and clinical significance of miR-452-5p in LUSC remain unclear. The Cancer Genome Atlas (TCGA) and the Gene Expression Omnibus (GEO) aim to provide a comprehensive understanding of cancer at the molecular level using genomic analyses, including large-scale genome sequences and microarrays for improving the diagnosis, treatment and prevention of cancer. In the present study, the expression level of miR-452-5p in LUSC was confirmed using the GEO and TCGA databases for the purpose of reducing the errors caused by sample size and study population. Gene ontology (GO) and pathway enrichment analyses of miR-452-5p target genes were also performed for clarification of the molecular mechanism of miR-452-5p in LUSC.

\section{Materials and methods}

Extraction of data on miR-452-5p expression in LUSC from TCGA and GEO. As illustrated in Fig. 1, information regarding miR-452-5p expression and clinical characteristics of patients with LUSC was extracted from TCGA (https://tcga-data.nci. nih.gov/docs/publications/tcga/) and GEO (https://www.ncbi. nlm.nih.gov/geo/) for this retrospective study. The following strategy was used to search in GEO datasets: 'Lung' OR 'pulmonary' OR 'respiratory' OR 'bronchi' OR 'alveoli' AND ‘cancer' OR ‘carcinoma' OR 'tumor' OR 'neoplas*' OR 'malignan*'. The resulting eligible records, including miRNA microarray and RNA-seq datasets, were reviewed. The inclusion criteria were as follows: i) Diagnosis of patient with lung squamous cell carcinoma; ii) detection of miR-452-5p expression level in tissue or blood samples and iii) availability of original expression profiling data of $\mathrm{miR}-452-5 \mathrm{p}$ in both cancerous and non-cancerous specimens. The exclusion criteria were as follows: i) Datasets from research on cell lines or animals; ii) cancerous or non-cancerous groups with small sample sizes $(\mathrm{n}<10)$, and iii) poor-quality profiling expression data $(0$, 0.1 or 1 ) that accounts for $>30 \%$ of the total expression data. Independent investigators (Xiaoning Gan and Tingqing Gan) reviewed the datasets that met the criteria and extracted the appropriate datasets. Discrepancies between the decisions of the two investigators were resolved by discussion among all authors. Next, the data were summarized and analyzed using Microsoft Office 2007 software package (Excel and Office programmes), SPSS (version 22.0; IBM Corp., Armonk, NY, USA) and R (version 3.3.0; https://www.r-project.org/). The primary expression data of miR-452-5p were $\log _{2}$-transformed for further study.

Prediction of miR-452-5p target genes. The prediction was performed using online bioinformatic software, including EMBL-EBI (https://www.ebi.ac.uk/), Targetminer (https://www. isical.ac.in/ bioinfo_miu/targetminer20.htm), DIANA-microT (http://carolina.imis.athena-innovation.gr/diana_tools/web/index. php), miRWalk and databases associated with miRWalk (TargetScan, miRanda, Pictar2, RNAhybrid, miRDB, RNA22-HAS, TargetMiner, EMBL-EBI, DIANA-microT, mirbridge, miRMap, miRNAMap and PITA). The target genes of miR-452-5p were searched in the PubMed (https://www.ncbi. nlm.nih.gov/pubmed) and EMBASE (https://www.embase.com) databases using the terms: 'Cancer', 'tumor', 'carcinoma', 'neoplasm', 'malignant', 'malignancy' and 'miR-452'. Potential miR-452-5p target genes that were positive in all seven software programs of the 14 aforementioned prediction software or have been previously experimentally confirmed were used for further analyses.

Bioinformatic analysis of miR-452-5p target genes. Potential miR-452-5p target genes were subjected to GO and pathway analyses using the Database for Annotation, Visualization and Integrated Discovery (DAVID; https://david.ncifcrf.gov/) and EnrichmentMap (a Cytoscape plugin) (30). The Kyoto Encyclopedia of Genes and Genomes database (KEGG; http://www.kegg.jp/) was used to identify the signaling pathways associated with the target genes. The Search Tool for the Retrieval of Interacting Genes/Proteins (STRING; http://string-db.org/) database was utilized for the selection of hub genes that were most likely involved in the strategic pathway associated with LUSC. Hub genes were identified by the combined score summarized in the protein-protein interaction (PPI) network of STRING with Cytoscape $(31,32)$.

Statistical analyses. Statistical analyses were performed using SPSS (version 22.0; IBM Corp.), StataSE (version 12.0; StataCorp LP, College Station, TX, USA), GraphPad Prism (version 5.0; GraphPad Software Inc., La Jolla, CA, USA), $\mathrm{R}$ version 3.3.0 and Microsoft Office 2007 software packages. Student's t-test (Paired or unpaired t-test were utilized according to the data type analyzed) or the Mann-Whitney test was used to examine the difference between the 2 groups. One-way analysis of variance followed by Student-Newman-Keuls (SNK) post-hoc test was employed to compare between $\geq 3$ groups. Spearman's rank correlation coefficient analysis was applied to analyze the correlation between miR-452-5p expression and clinicopathological parameters or hub genes. Receiver operating characteristic (ROC) curve analysis was used to evaluate the diagnostic value of $\mathrm{miR}-452-5 \mathrm{p}$ in patients with LUSC. The effect of miR-452-5p expression and clinical risk factors on the survival of patients with LUSC was statistically analyzed using the Cox proportional hazards regression model. A meta-analysis was performed using StataSE (version 12.0). A forest plot of standard mean deviation (SMD) was analyzed to confirm the expression level of miR-452-5p in LUSC. If the standard mean deviation (SMD) was $<0$ and the $95 \% \mathrm{CI}$ was $<0$, the expression of $\mathrm{miR}-452-5 \mathrm{p}$ was considered to be lower in cancerous specimens compared with non-cancerous specimens. By contrast, if the overall SMD was $>0$ and the $95 \%$ CI was $>0$, the expression of miR-452-5p was considered to be higher in cancerous specimens compared with non-cancerous specimens. Publication bias was assessed using Begg's funnel plot and Egger's test. $\mathrm{P}<0.05$ was considered to indicate a statistically significant difference. 


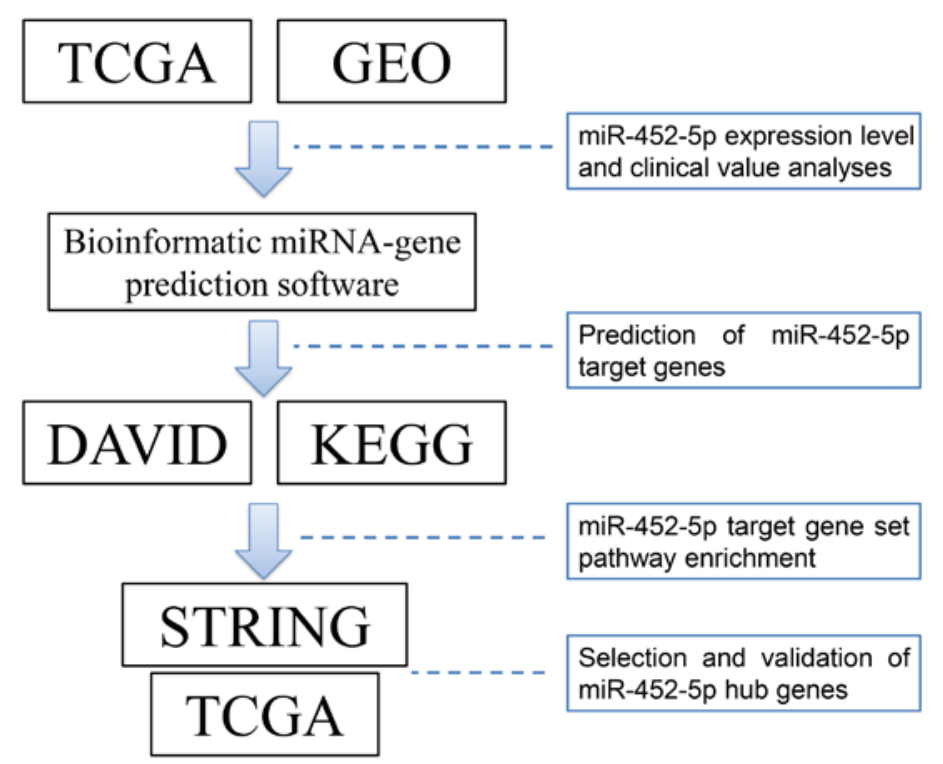

Figure 1. Flow diagram outlining the procedures of the present study. miRNA, microRNA. TCGA, The Genome Cancer Atlas; GEO, Gene Expression Omnibus; DAVID, Database for Annotation, Visualization and Integrated Discovery; KEGG, Kyoto Encyclopedia of Genes and Genomes; STRING, Search Tool for the Retrieval of Interacting Genes/Proteins.
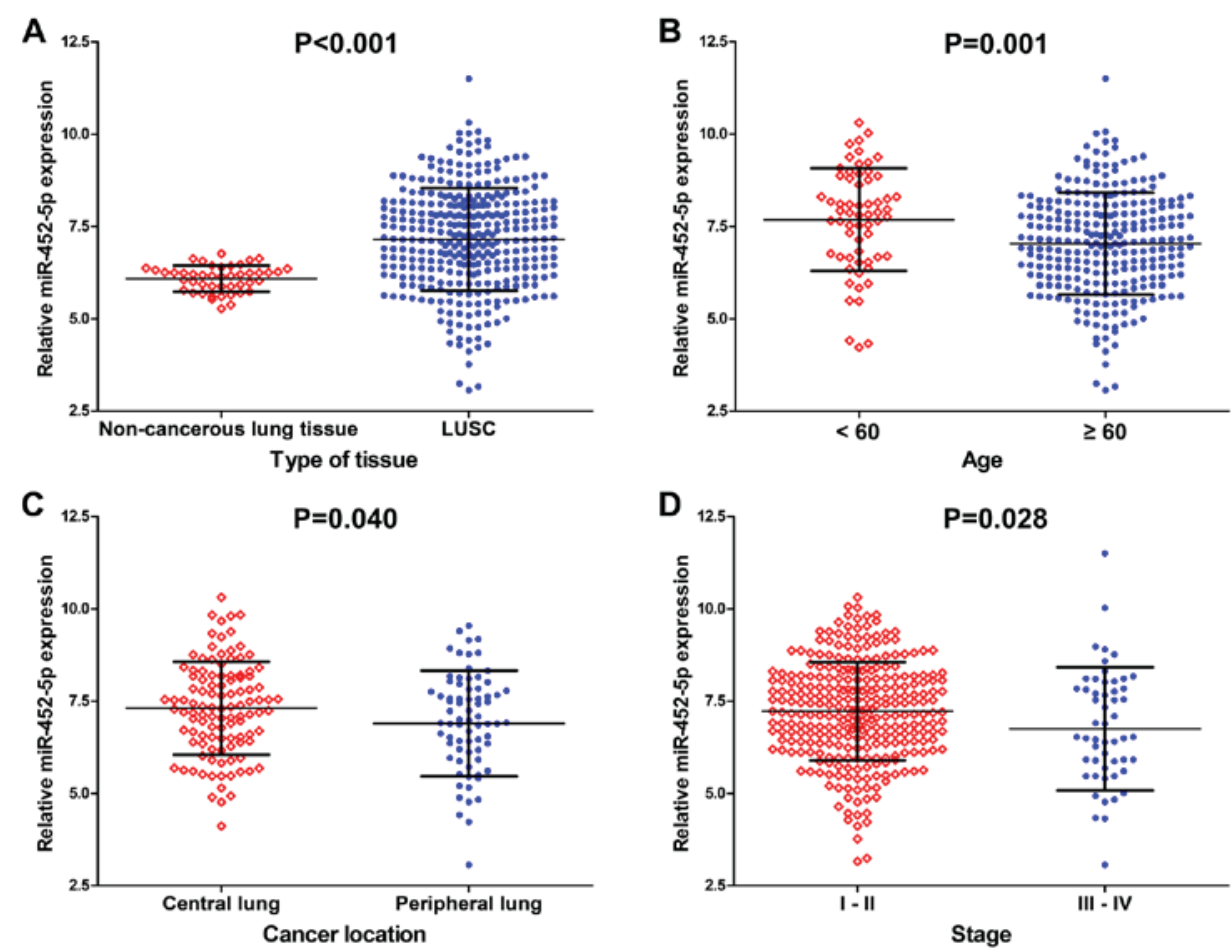

Figure 2. Expression of miR-452-5p in LUSC and its association with clinicopathological parameters. (A) The expression of miR-452-5p was upregulated in LUSC tissues compared with adjacent lung tissues. (B) The miR-452-5p expression level in patients $<60$ years was increased compared with patients $\geq 60$ years. (C) The miR-452-5p expression level in patients with a tumor located in the central lung was increased compared with patients with a tumor located in the peripheral lung. (D) The miR-452-5p expression level in patients with stages I-II LUSC was increased compared with patients with stages III-IV LUSC. LUSC, lung squamous cell carcinoma; miRNA, microRNA.

\section{Results}

Association between miR-452-5p expression and clinicopathological features in LUSC. The data on 387 cases of LUSC (342 cancerous and 45 non-cancerous adjacent lung tissues) patients with differential miR-452-5p expression were extracted from the TCGA database. The results indicated that the expression of miR-452-5p in LUSC tissues was higher compared with adjacent lung tissues $(7.1525 \pm 1.39063$ vs. 6.0885 $\pm 0.35298 ; \mathrm{P}<0.001 ;$ Fig. 2A; Table I).

The associations between the levels of miR-452-5p expression and age, cancer location, and TNM stage were 
Table I. Association between the expression of miR-452-5p and clinicopathological parameters in LUSC as analyzed using data from The Cancer Genome Atlas.

\begin{tabular}{|c|c|c|c|c|}
\hline \multirow[b]{2}{*}{ Clinicopathological features } & \multirow[b]{2}{*}{$\mathrm{n}$} & \multicolumn{3}{|c|}{ miR-452-5p expression $\left(\log _{2}\right)$} \\
\hline & & Mean \pm SD & t-test & P-value \\
\hline \multicolumn{5}{|l|}{ Tissue } \\
\hline Adjacent non-cancerous lung tissue & 45 & $6.0885 \pm 0.35298$ & \multirow[t]{2}{*}{$Z=-6.053^{\mathrm{a}}$} & \multirow[t]{2}{*}{$<0.001$} \\
\hline LUSC & 342 & $7.1525 \pm 1.39063$ & & \\
\hline \multicolumn{5}{|l|}{ Age (years) } \\
\hline$<60$ & 62 & $7.6847 \pm 1.39161$ & \multirow[t]{2}{*}{3.359} & \multirow[t]{2}{*}{0.001} \\
\hline$\geq 60$ & 274 & $7.0333 \pm 1.37623$ & & \\
\hline \multicolumn{5}{|l|}{ Sex } \\
\hline Female & 85 & $7.0867 \pm 1.30046$ & \multirow[t]{2}{*}{-0.503} & \multirow[t]{2}{*}{0.616} \\
\hline Male & 257 & $7.1742 \pm 1.42095$ & & \\
\hline \multicolumn{5}{|l|}{ Ethnicity } \\
\hline Caucasian descent & 252 & $7.1228 \pm 1.42366$ & \multirow[t]{3}{*}{$\mathrm{F}=1.985^{\mathrm{b}}$} & \multirow[t]{3}{*}{0.139} \\
\hline African descent & 24 & $7.4428 \pm 1.32204$ & & \\
\hline Asian descent & 6 & $6.1575 \pm 1.78242$ & & \\
\hline \multicolumn{5}{|l|}{ Recurrence } \\
\hline No & 139 & $7.2663 \pm 1.29109$ & \multirow[t]{2}{*}{-0.315} & \multirow[t]{2}{*}{0.753} \\
\hline Yes & 30 & $7.3517 \pm 1.57974$ & & \\
\hline \multicolumn{5}{|l|}{ Cancer location } \\
\hline Central lung & 109 & $7.3056 \pm 1.25173$ & \multirow[t]{2}{*}{2.069} & \multirow[t]{2}{*}{0.040} \\
\hline Peripheral lung & 74 & $6.8924 \pm 1.42939$ & & \\
\hline \multicolumn{5}{|l|}{ Smoke } \\
\hline$\leq 20$ & 29 & $7.2479 \pm 1.77796$ & \multirow[t]{2}{*}{0.379} & \multirow[t]{2}{*}{0.705} \\
\hline$>20$ & 258 & $7.1428 \pm 1.37157$ & & \\
\hline \multicolumn{5}{|l|}{ Stage } \\
\hline I-II & 285 & $7.2259 \pm 1.32747$ & \multirow[t]{2}{*}{$\mathrm{Z}=-2.191^{\mathrm{a}}$} & \multirow[t]{2}{*}{0.028} \\
\hline III-IV & 54 & $6.7484 \pm 1.67113$ & & \\
\hline Tumor grade & & & & \\
\hline $\mathrm{T} 1-2$ & 272 & $7.1847 \pm 1.36195$ & 0.844 & 0.399 \\
\hline $\mathrm{T} 3-4$ & 70 & $7.0273 \pm 1.50065$ & & \\
\hline Nodal metastasis & & & & \\
\hline No & 219 & $7.2583 \pm 1.26109$ & $\mathrm{Z}=-1.901^{\mathrm{a}}$ & 0.057 \\
\hline Yes & 123 & $6.9642 \pm 1.58355$ & & \\
\hline Metastasis & & & & \\
\hline No & 261 & $7.1327 \pm 1.35815$ & -0.471 & 0.638 \\
\hline Yes & 81 & $7.2161 \pm 1.49758$ & & \\
\hline Tumor status & & & & \\
\hline Tumor-free & 216 & $9.2886 \pm 1.28058$ & -0.682 & 0.496 \\
\hline With tumor & 57 & $9.4231 \pm 1.48230$ & & \\
\hline
\end{tabular}

${ }^{\mathrm{a}}$ Mann Whitney test was used for the comparison between 2 groups; ${ }^{\mathrm{b}}$ one-way analysis of variance was used for analysis between $\geq 3$ groups. LUSC, lung squamous cell carcinoma; miRNA, microRNA; SD, standard deviation; TNM, tumor-node metastasis.

statistically significant. miR-452-5p expression in patients $<60$ years was significantly increased compared with patients $\geq 60$ years ( $\mathrm{P}=0.001$; Fig. $2 \mathrm{~B}$ ). The expression of miR-452-5p in patients with a tumor located in the central lung was significantly increased compared with patients with a tumor located in the peripheral lung $(\mathrm{P}=0.040$; Fig. $2 \mathrm{C})$. Additionally, the level of miR-452-5p expression in patients with TNM stages I-II LUSC was significantly increased compared with patients with patients with stages III-IV LUSC ( $\mathrm{P}=0.028$; Fig. 2D). Spearman's rank correlation coefficient analysis demonstrated that the expression of miR-452-5p was negatively correlated with age $(r=-0.187 ; P=0.001)$ and $T N M$ stage $(r=-0.119$; 

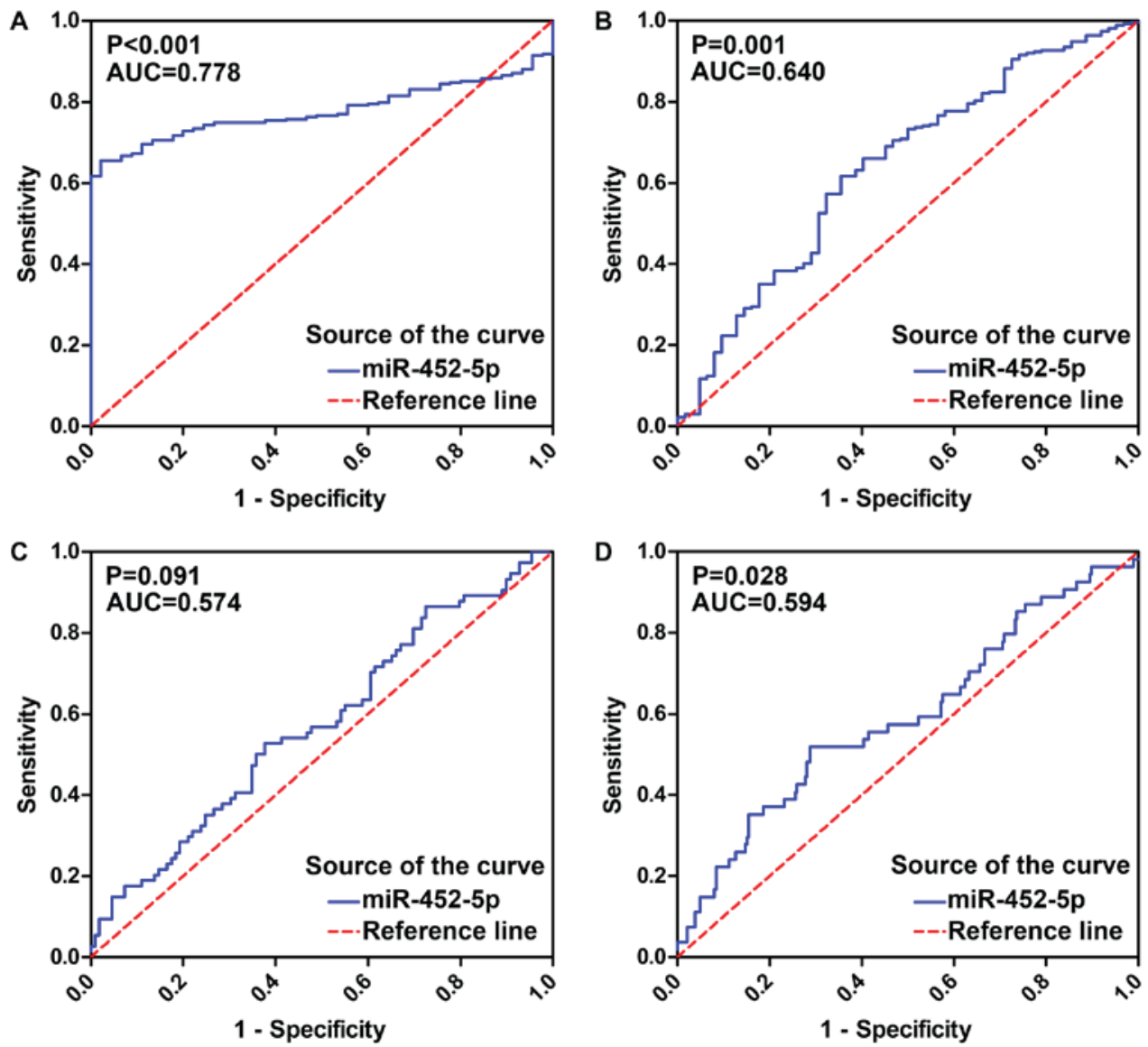

Figure 3. ROC curve analyses of the diagnostic value of miR-452-5p in LUSC. (A) ROC curve of miR-452-5p employed for the diagnosis of LUSC. (B) ROC curve demonstrating the association of miR-452-5p with the age of patients with LUSC. (C) ROC curve demonstrating the association of miR-452-5p with cancer location of patients with LUSC. (D) ROC curve demonstrating the association of miR-452-5p with the tumor-node metastasis stage of patients with LUSC. LUSC, lung squamous cell carcinoma; miRNA, microRNA; ROC, receiver-operating characteristic.

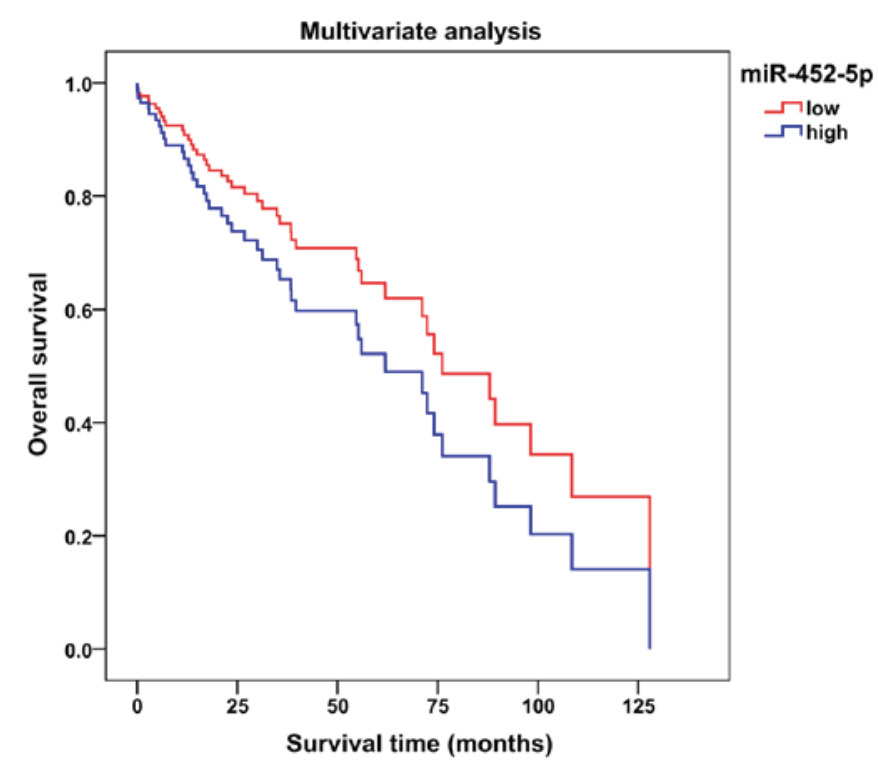

Figure 4. Multivariate analysis of the effect of miR-452-5p expression on the overall survival of patients with lung squamous cell carcinoma. miRNA, microRNA.

$\mathrm{P}=0.028$ ) but was not significantly correlated with other clinical parameters.
Diagnostic value of miR-452-5p expression in LUSC. An ROC was generated to verify the predictive performance of miR-452-5p expression levels and various clinical parameters in LUSC (Fig. 3). The AUC of miR-452-5p expression for the diagnosis of LUSC was 0.778 (95\% CI, 0.734-0.821; P<0.001) with a sensitivity of $65.5 \%$, a specificity of $97.8 \%$ and a diagnostic threshold value of 6.632 . The AUC of miR-452-5p expression for age was 0.640 (95\% CI, 0.561-0.718; $\mathrm{P}=0.001$ ). Furthermore, in LUSC patients with different tumor location and TNM stage, the AUC values were 0.574 (95\% CI, $0.489-0.658 ; \mathrm{P}=0.091)$ and $0.594(95 \% \mathrm{CI}, 0.507-0.681$; $\mathrm{P}=0.028$ ), respectively.

Prognostic value of miR-452-5p in LUSC. An average value of 7.1525 was selected as the miR-452-5p expression level threshold to evaluate the association between miR-452-5p expression levels and the survival of patients with LUSC. The multivariate survival curve suggested that patients with LUSC and a low miR-452-5p expression may have longer overall survival (time from randomization until mortality from any cause) compared with patients with LUSC and a high miR-452-5p expression (Fig. 4; Table II). It was not possible to determine whether miR-452-5p could be a prognostic factor in patients with LUSC [univariate hazard ratio (HR), 0.981; 95\% CI, 0.648-1.487; $\mathrm{P}=0.928$; multivariate HR, 1.492; 95\% CI, 0.791-2.814; $\mathrm{P}=0.216]$. 
Table II. Multivariate analysis of clinicopathological parameters for overall survival in lung squamous cell carcinoma.

\begin{tabular}{lccr}
\hline A, Univariate analysis & & & \\
\hline Clinicopathological features & HR & $95 \%$ CI & P-value \\
\hline $\begin{array}{l}\text { Age } \\
>3 \text { vs. } \leq 3\end{array}$ & 1.163 & $0.734-1.844$ & 0.521 \\
$\begin{array}{l}\text { Tumor grade } \\
\text { T3-4 vs. T1-2 }\end{array}$ & 1.489 & $1.016-2.182$ & 0.041 \\
$\begin{array}{l}\text { Nodal metastasis } \\
\text { Yes vs. no }\end{array}$ & & & 0.221 \\
$\begin{array}{l}\text { Metastasis } \\
\text { Yes vs. no }\end{array}$ & 1.222 & $0.886-1.686$ & 0.222 \\
$\begin{array}{l}\text { TNM stage } \\
\text { III-IV vs. I-II }\end{array}$ & 1.343 & $0.836-2.156$ & 0.049 \\
$\begin{array}{l}\text { Cancer location } \\
\text { Peripheral lung vs. central lung } \\
\text { miR-452-5p expression } \\
\text { High vs. low }\end{array}$ & 1.441 & $1.001-2.075$ & 0.377 \\
\hline
\end{tabular}

B, Multivariate analysis

\begin{tabular}{lccc}
\hline Clinicopathological features & HR & $95 \%$ CI & P-value \\
\hline $\begin{array}{l}\text { Age } \\
>3 \text { vs. } \leq 3\end{array}$ & 1.596 & $0.535-4.760$ & 0.401 \\
$\begin{array}{l}\text { Tumor grade } \\
\text { T3-4 vs. T1-2 }\end{array}$ & 0.999 & $0.416-2.396$ & 0.998 \\
$\begin{array}{l}\text { Nodal metastasis } \\
\text { Yes vs. no }\end{array}$ & & & 0.490 \\
$\begin{array}{l}\text { Metastasis } \\
\text { Yes vs. no }\end{array}$ & 1.307 & $0.611-2.793$ & 0.691 \\
$\begin{array}{l}\text { TNM stage } \\
\text { III-IV vs. I-II }\end{array}$ & 1.358 & $0.301-6.126$ & 0.494 \\
$\begin{array}{l}\text { Cancer location } \\
\text { Peripheral lung vs. central lung } \\
\text { miR-452-5p expression } \\
\text { High vs. low }\end{array}$ & 1.358 & $0.566-3.259$ & 0.060 \\
\hline
\end{tabular}

HR, hazard ratio; CI, confidence interval; miRNA, microRNA; TNM, tumor-node metastasis.

Verification of miR-452-5p expression in LUSC with meta-analysis. A total of 720 cancerous and non-cancerous samples from 7 eligible GEO datasets (including 333 cases from 7 eligible GEO datasets and 387 cases from TCGA) were screened in the meta-analysis (data not shown). The miR-452-5p expression levels in LUSC of each GEO dataset are illustrated in Fig. 5 and shown in Table III. In the meta-analysis, the random-effects model was used to calculate the pooled SMD and 95\% CI due to the high heterogeneity of the data $\left(\mathrm{I}^{2}=59.3 \% ; \mathrm{P}=0.016\right)$. These results indicated that the expression of miR-452-5p in LUSC was significantly increased compared with non-cancerous specimens (SMD,
0.372; 95\% CI, 0.020-0.724; $\mathrm{z}=2.07 ; \mathrm{P}=0.038$ ) (Fig. 6A). The points, which represent individual studies, were symmetrically arranged in the Begg's funnel plot $(\mathrm{P}=0.711)$ and the $\mathrm{P}$-values calculate from the Egger's test were $>0.05(\mathrm{P}=0.810)$, which indicates that there was no publication bias in the studies (Fig. 6B).

Potential target genes of miR-452-5p. A total of 17,094 miR-452-5p candidate target genes were screened using 14 prediction programs. A total of 249 miR-452-5p target genes were searched and subjected to GO and pathway analyses. This included 248 candidates that were verified as target 
Table III. Relative expression of miR-452-5p in LUSC analyzed using Gene Expression Omnibus datasets.

\begin{tabular}{|c|c|c|c|c|c|}
\hline \multirow[b]{2}{*}{ Dataset } & \multirow[b]{2}{*}{ Tissue } & \multirow[b]{2}{*}{$\mathrm{n}$} & \multicolumn{3}{|c|}{ miR-452-5p expression $\left(\log _{2}\right)$} \\
\hline & & & Mean \pm SD & t-test & P-value \\
\hline \multirow[t]{2}{*}{ GSE40738 } & Non-cancer & 72 & $-0.1856 \pm 0.12812$ & -0.226 & 0.822 \\
\hline & LUSC & 34 & $-0.1796 \pm 0.12344$ & & \\
\hline \multirow[t]{2}{*}{ GSE19945 } & Non-cancer & 8 & $-1.3640 \pm 1.51488$ & -2.213 & $0.049^{b}$ \\
\hline & LUSC & 5 & $0.2678 \pm 0.76523$ & & \\
\hline \multirow[t]{2}{*}{ GSE16025 } & Non-cancer & 10 & $2.5530 \pm 0.10050$ & 0.447 & 0.656 \\
\hline & LUSC & 61 & $2.5420 \pm 0.06697$ & & \\
\hline \multirow[t]{2}{*}{ GSE25508 } & Non-cancer & 8 & $6.2369 \pm 1.86325$ & $-1.085^{\mathrm{a}}$ & 0.314 \\
\hline & LUSC & 8 & $6.3974 \pm 0.46815$ & & \\
\hline \multirow[t]{2}{*}{ GSE74190 } & Non-cancer & 44 & $-0.4829 \pm 1.84267$ & -0.769 & 0.445 \\
\hline & LUSC & 30 & $-0.1329 \pm 2.03639$ & & \\
\hline \multirow[t]{2}{*}{ GSE47525 } & Non-cancer & 14 & $2.8929 \pm 0.51361$ & 0.213 & 0.840 \\
\hline & LUSC & 5 & $2.7800 \pm 1.14324$ & & \\
\hline \multirow[t]{2}{*}{ GSE51853 } & Non-cancer & 5 & $-0.7281 \pm 0.47630$ & -2.062 & $0.047^{\mathrm{b}}$ \\
\hline & LUSC & 29 & $-0.1516 \pm 0.59057$ & & \\
\hline
\end{tabular}

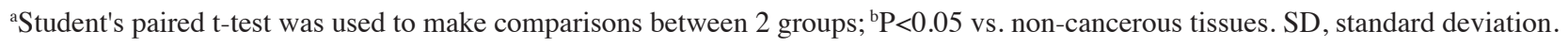

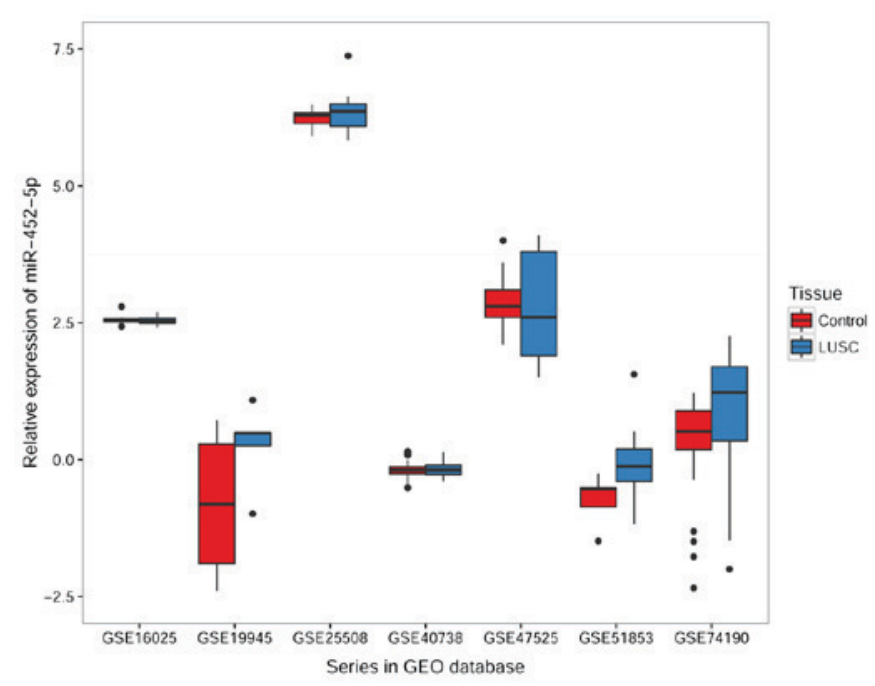

Figure 5. Relative expression levels of miR-452-5p in LUSC analyzed in 7 GEO datasets. Marginally significant upregulation of miR-452-5p in LUSC tissue compared with non-cancerous tissue was detected in GSE19945 (0.2678 \pm 0.76523 vs. $-1.3640 \pm 1.51488, \mathrm{P}=0.049)$ and GSE51853 $(-0.1516 \pm 0.59057$ vs. $-0.7281 \pm 0.47630, P=0.047)$ datasets. No statistical significance was identified in the GSE40738, GSE16025, GSE25508, GSE74190 and GSE47525 datasets. GEO, Gene Expression Omnibus; LUSC, lung squamous cell carcinoma.

genes by $\geq 7$ programs and 1 target gene that was validated by experiments.

GO and KEGG pathway analyses. The DAVID database was used to perform GO analysis of the 249 target genes of miR-452-5p (Fig. 7A). The results indicated that, at the level of biological process (BP), target gene sets of miR-452-5p were closely associated with 'regulation of transcription', 'commissural neuron axon guidance' and 'transcription' $(\mathrm{P}<0.01)$. In terms of cellular components $(\mathrm{CC})$, the target genes were mainly involved in the assembly of cellular structures, including 'nucleoplasm', 'nucleus' and 'cytoplasmic vesicle membrane' $(\mathrm{P}<0.01)$. Regarding molecular function $(\mathrm{MF})$, the genes were mainly enriched in protein binding, chromatin binding and zinc ion binding $(\mathrm{P}<0.01)$. The results from the KEGG pathway analysis indicated that the predicted miR-452-5p target gene sets were significantly enriched in signaling pathways that are involved in the regulation of pluripotency of stem cells, oocyte meiosis and cell cycle $(\mathrm{P}<0.05)$.

The visualization function of Cytoscape was used to graphically display the results of $\mathrm{GO}(\mathrm{P}<0.01$; $\mathrm{Q}<0.1$; overlap coefficient $>0.5)$ and KEGG $(\mathrm{P}<0.05$; $\mathrm{Q}<0.5$; overlap coefficient $>0.5$ ) enrichment annotation analyses, allowing a more intuitive presentation of the associations between the pathways (Fig. 7B).

PPI network analysis for the selection of hub genes. The network consisted of 249 nodes and 118 edges. Among the 249 miR-452-5p target genes, 95 target genes were connected based on experiment, co-expression, neighborhood or other evidence summarized by STRING. The disconnected target genes $(n=154)$ were removed from the network (Fig. 8). Finally, 10 hub genes (nodes connected with more than 6 edges) were identified from the 95 target genes. These hub genes were SMAD family member 4 (SMAD4), myocyte enhancer factor $2 \mathrm{C}$ (MEF2C), tyrosine 3-monooxygenase/tryptophan 5-monooxygenase activation protein $\varepsilon$ (YWHAE), SMAD family member 2 (SMAD2), SWI/SNF related, matrix associated, actin-dependent regulator of chromatin, subfamily a, member 4 (SMARCA4), tyrosine 3-monooxygenase/tryptophan 5-monooxygenase activation protein $\beta$ (YWHAB), platelet activating factor acetylhydrolase $1 \mathrm{~b}$ regulatory subunit 1 (PAFAH1B1), 

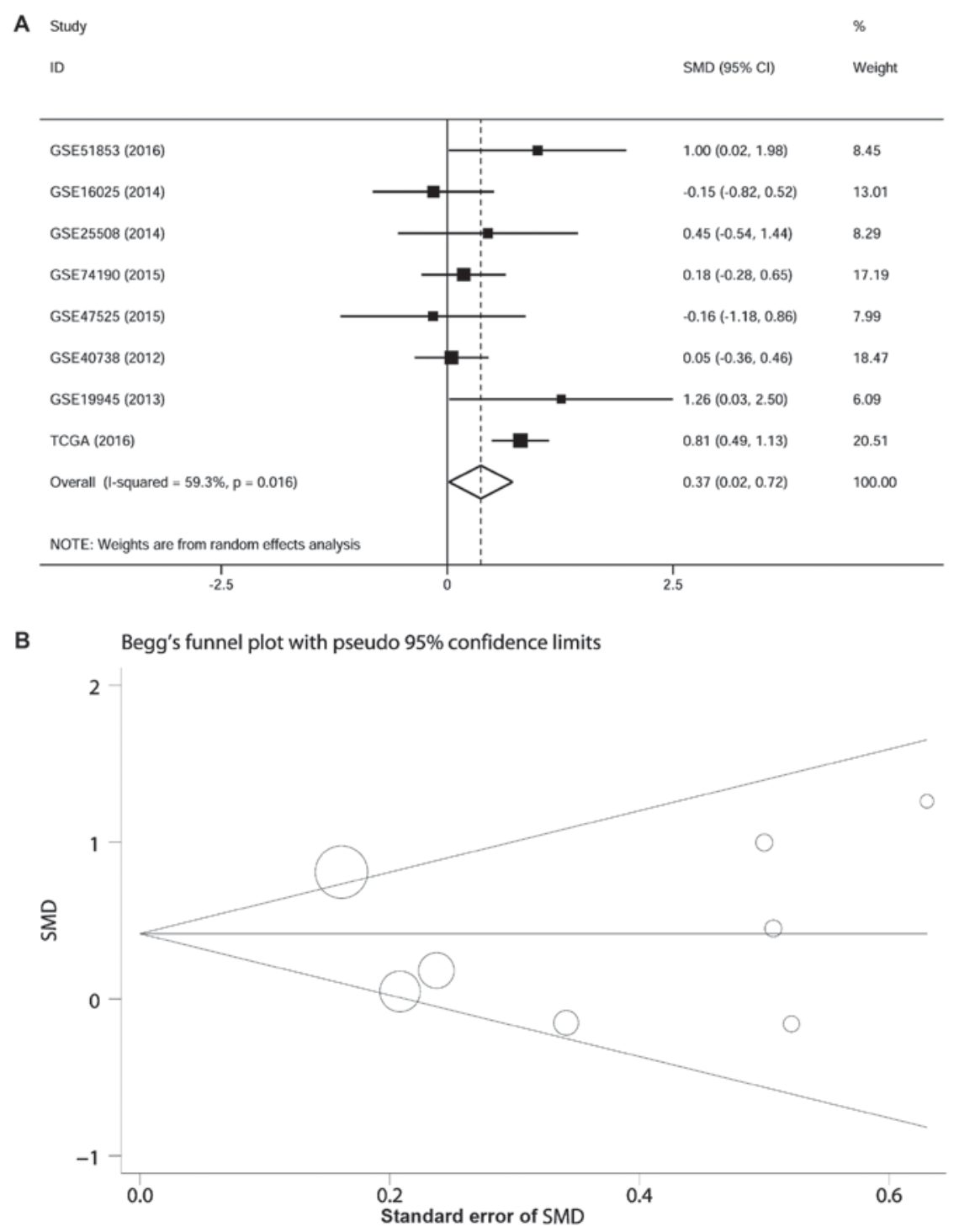

Figure 6. Meta-analysis of miR-452-5p expression in LUSC using TCGA and GEO datasets. (A) Forest plot of SMD to confirm the high expression of miR-452-5p in LUSC. (B) Funnel plot of 8 datasets for analysis of publication bias. LUSC, lung squamous cell carcinoma; TCGA, The Cancer Genome Axis; GEO, Gene Expression Omnibus; SMD, standard mean deviation; CI, confidence interval.

protein kinase cAMP-dependent type II regulatory subunit $\beta$ (PRKAR2B), cyclin dependent kinase inhibitor 1B (CDKN1B) and replication protein A1 (RPA1). Among these 10 hub genes, 5 hub genes, including SMAD4, SMAD2, CDKN1B, YWHAE and YWHAB, were significantly enriched in 'cell cycle'.

Association between the expression of miR-452-5p and the 5 hub genes that are involved in cell cycle. The expression levels of 5 hub genes in LUSC were demonstrated with the TCGA dataset, including SMAD4, SMAD2, CDKN1B, YWHAE and YWHAB. The results indicated that the expression of CDKN1B and SMAD4 was significantly downregulated in LUSC tissues compared with non-cancerous lung tissues ( $\mathrm{P}=0.023$ and $\mathrm{P}<0.001$, respectively), while YWHAE expression was significantly upregulated in LUSC compared with control $(\mathrm{P}<0.001)$. There was no significant difference in the expression of SMAD2 or YWHAB in LUSC tissues compared with non-cancerous lung tissue (Fig. 9A; Table IV). Furthermore, Spearman's rank correlation coefficient analysis demonstrated that miR-452-5p expression was negatively correlated with CDKN1B expression in LUSC ( $\mathrm{r}=-0.163$; $\mathrm{P}=0.003$ ). However, miR-452-5p expression was not significantly correlated with the expression of SMAD4, SMAD2, YWHAE or YWHAB (Fig. 9B). In addition, in non-cancerous lung tissue, miR-452-5p was not correlated with CDKN1B expression $(\mathrm{r}=-0.013 ; \mathrm{P}=0.937)$. These results suggested that miR-452-5p may target CDKN1B in the carcinogenesis of LUSC.

\section{Discussion}

The present study indicated that miR-452-5p expression in LUSC was significantly upregulated compared with non-cancerous lung tissues, and the diagnostic value of miR-452-5p expression for LUSC was also confirmed. Correlation analysis indicated that the expression of miR-452-5p correlated with clinical parameters, including age and TNM stage. Additionally, the results indicate that patients with LUSC and high expression of miR-452-5p were associated with early tumor stage but shorter survival 
A
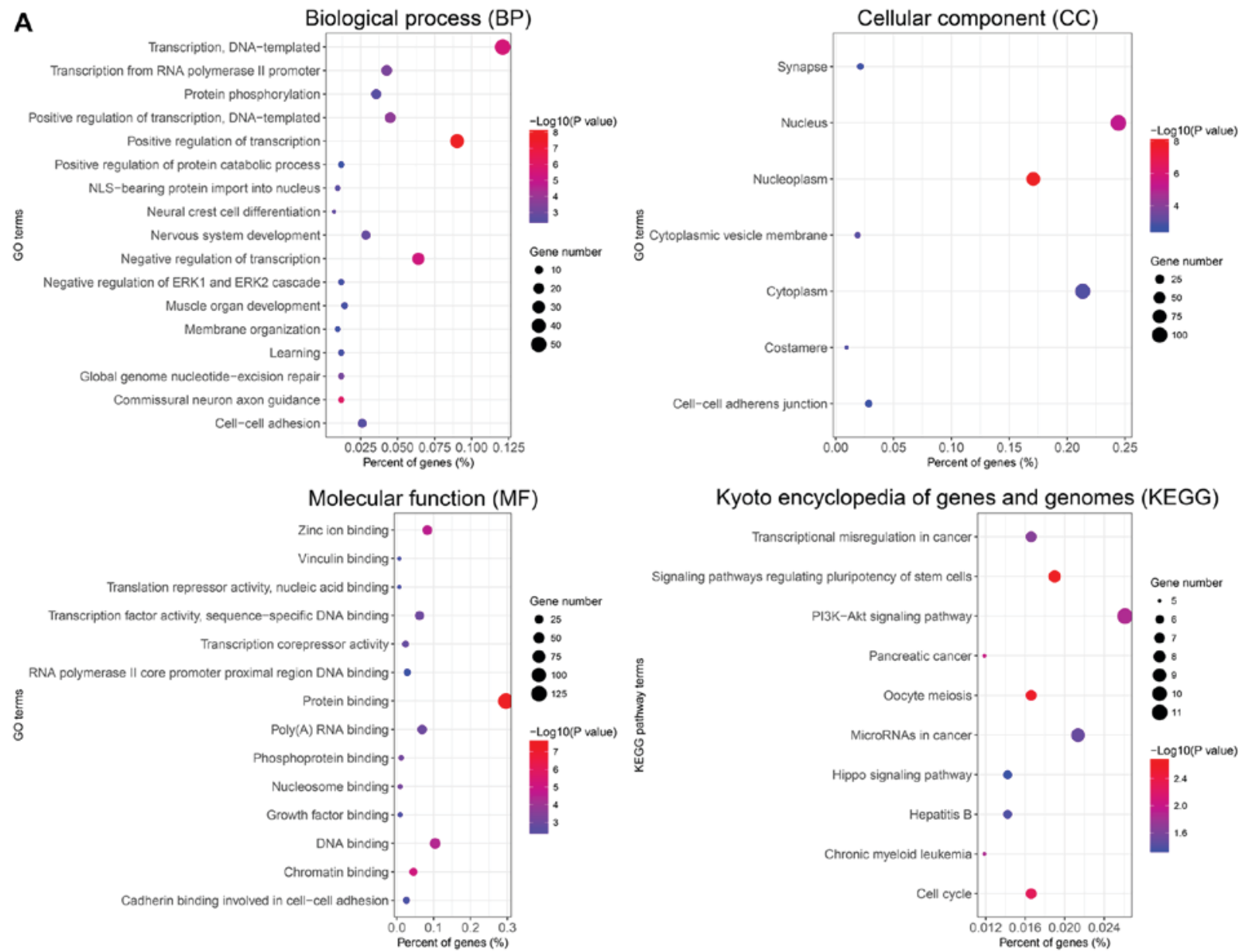

B
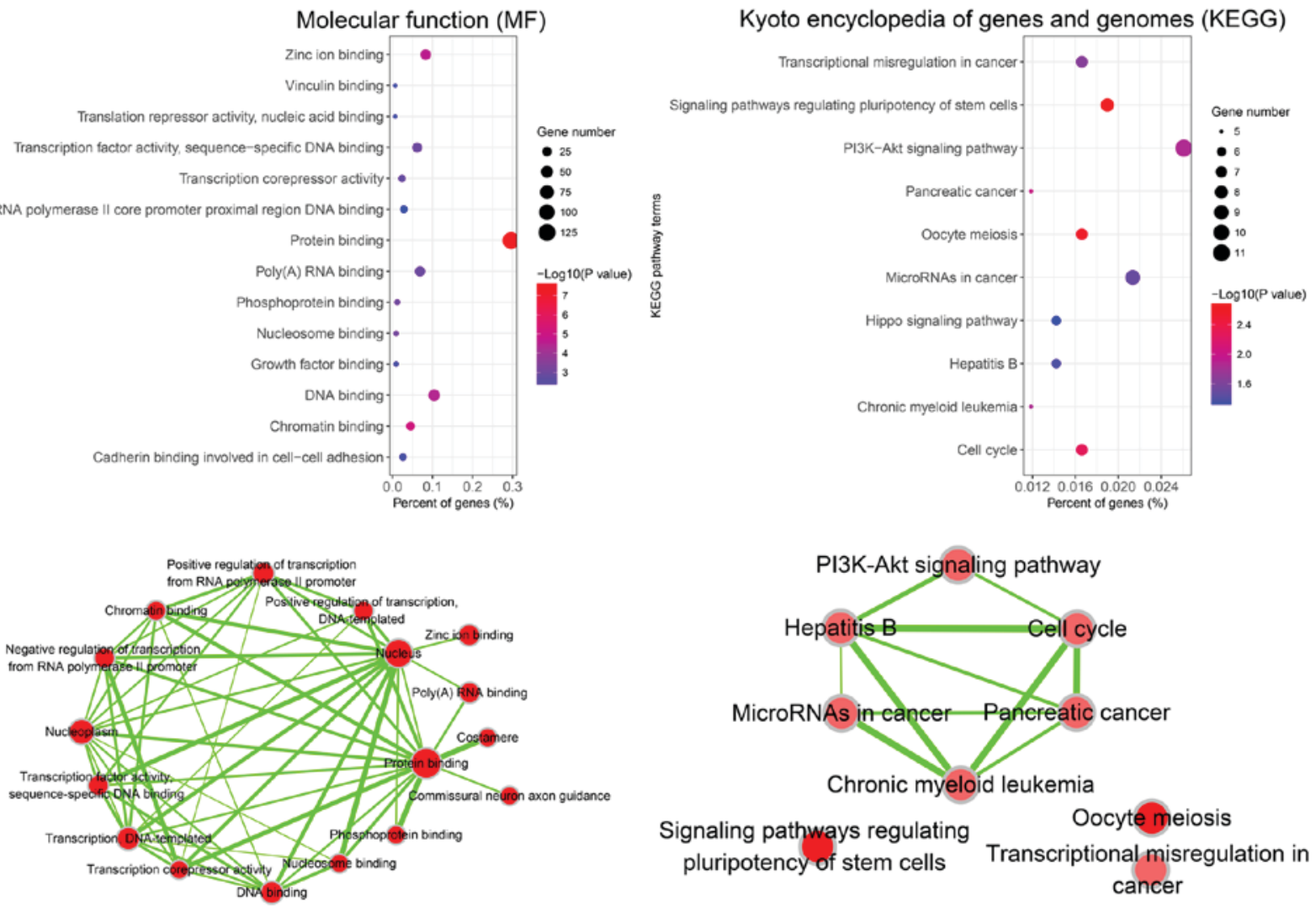

Figure 7. GO and KEGG pathway analyses with the prospective target genes of miR-452-5p. (A) The GO $(\mathrm{P}<0.01)$ and KEGG $(\mathrm{P}<0.05)$ annotation items of miR-452-5p target genes. (B) GO and KEGG pathways connected using EnrichmentMap due to the overlapping target genes. The intensity of the color indicates the P-value significance. The size of the nodes and edges is representative of the number of genes. GO, gene ontology; KEGG, Kyoto Encyclopedia of Genes and Genomes; miRNA, microRNA; PI3K, phosphoinositide-3-kinase.

time. There are two potential reasons that may lead to these apparent conflicting results. Firstly, patients with relatively higher expression of miR-452-5p were more likely to succumb to disease at the early stage, while patients with relative lower expression of miR-452-5p were more likely to survive until late stages of the disease. Secondly, a number of patients with high expression of miR-452-5p were unable to accept or refused the investigation due to severe symptoms caused by the disease. These findings indicate that miR-452-5p may serve an essential role in the carcinogenesis and progression of LUSC. Furthermore, 5 hub target genes of miR-452-5p that are known to be involved in the cell cycle were predicted and screened, which may guide future studies in elucidating the mechanism of LUSC. The results also demonstrate that among these 5 hub genes, the expression of CDKN1B was negatively correlated with miR-452-5p.

miRNAs mainly perform their biological functions by complete or incomplete complementary binding with the 3'-untranslated region (UTR) of mRNAs (33-37). miR-452-5p is located at Xq28 in humans, and it can target multiple genes and thus serves a potentially important role in the biological process of carcinogenesis via a variety of mechanisms. Hu et al (24) reported that miR-452-5p expression was downregulated in breast cancer, which may lead to resistance to adriamycin by targeting the insulin analogue, growth factor receptor 1 (IGF-1R). The downregulation of miR-452-5p may also lead 


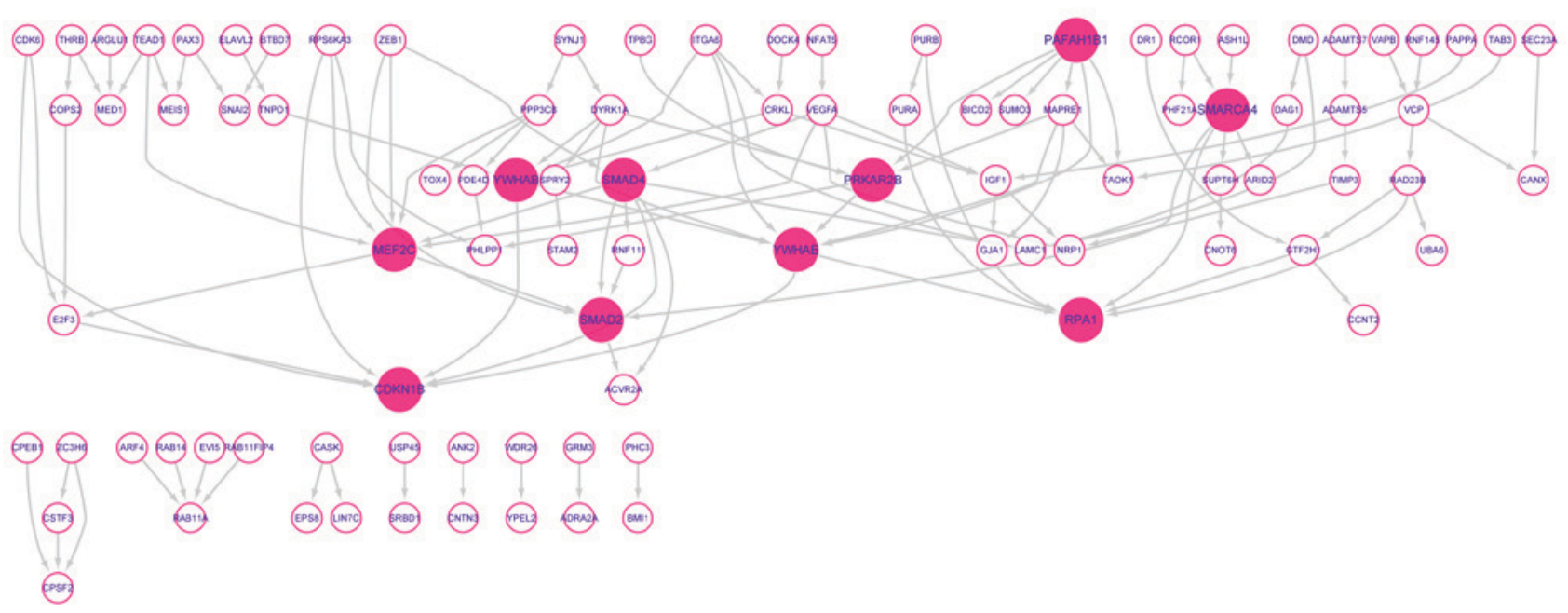

Figure 8. Protein-protein interaction network analysis of miR-452-5p target genes using Search Tool for the Retrieval of Interacting Genes/Proteins. A total of 10 hub genes (nodes connected with $>6$ edges) were screened from the network. Red, hub genes. Network nodes represent proteins, and network edges represent protein-protein associations. Interactions are based on experimental, gene neighborhood and co-expression evidence. Red, hub genes.
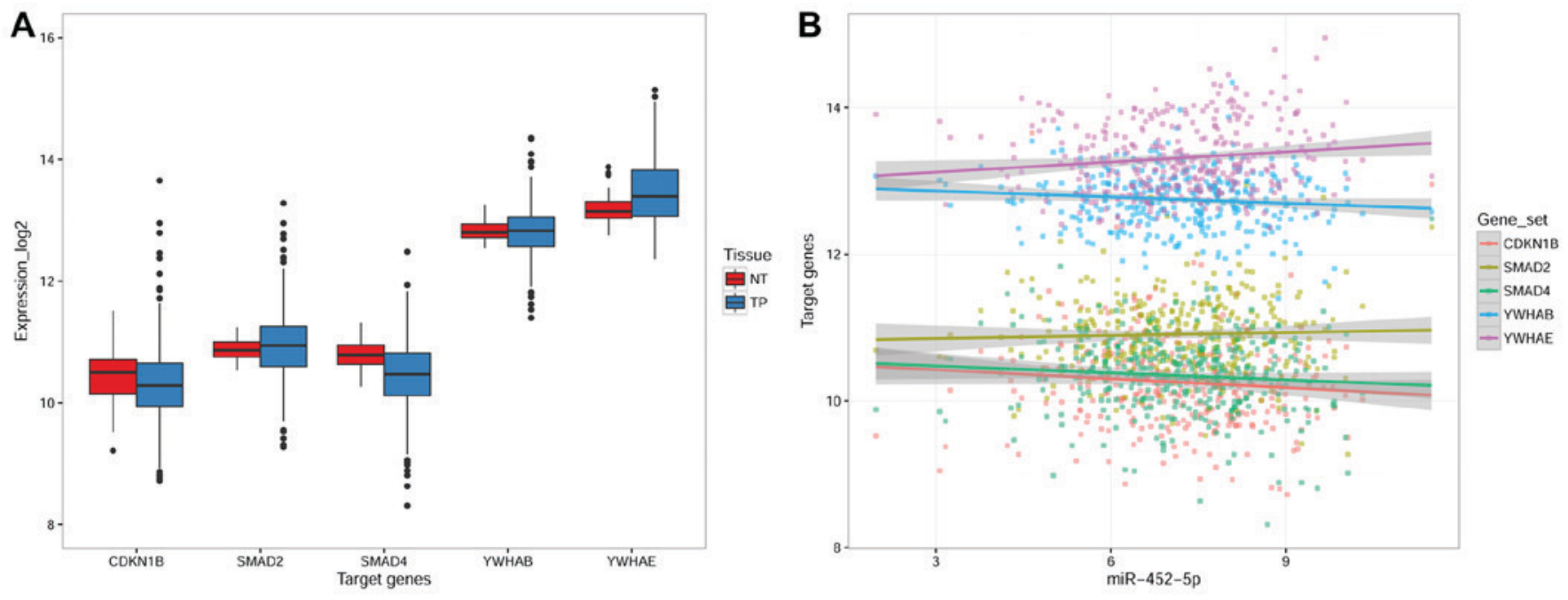

Figure 9. Expression of 5 hub genes that are involved in cell cycle and their association with miR-452-5p. (A) Relative expression levels of hub target genes of miR-452-5p in lung squamous cell carcinoma. (B) Curve fitting of data to illustrate the association between miR-452-5p expression and 5 hub genes. NT, normal tissue; TP, primary tumor; CDKN1B, cyclin dependent kinase inhibitor 1B; SMAD2, SMAD family member 2; SMAD 4, SMAD family member 4; YWHAB, tyrosine 3-monooxygenase/tryptophan 5-monooxygenase activation protein $\beta$; YWHAE, tyrosine 3-monooxygenase/tryptophan 5-monooxygenase activation protein $\varepsilon$.

to resistance to docetaxel by targeting the anaphase promoting complex subunit 4 (APC4) (24). Liu et al (26) reported that the expression of multifunctional stem cell regulatory factors, including SRY-box 2 (SOX2), was downregulated following upregulation of miR-452-5p expression in glioma cell lines. Furthermore, Liu et al (26) confirmed that the downregulation of miR-452-5p in glioma cells and tissues was correlated with promoter methylation. Zheng et al (23) reported high expression of miR-452-5p in hepatocellular carcinomas, suggesting that miR-452-5p could promote hepatocellular carcinoma by targeting CDKN1B (23). Zhang et al reported that miR-452-5p inhibited the proliferation, invasion and migration of NSCLC cells via the process of epithelial-mesenchymal transition (27). He et al (28) suggested that miR-452-5p enhanced the invasive capability of NSCLC cells by targeting BMI1 proto-oncogene, polycomb ring finger (28). However, the potential function and mechanism of miR-452-5p expression in LUSC remain unclear.

To date, to the best of our knowledge, He et al (29) is the only group to have reported that the downregulated expression of miR-452-5p was associated with clinicopathological features in patients with NSCLC. Although the nature of the present research study was similar to the study by He et al (29), the findings in our study are novel and provide further insights. Firstly, the present study analyzed a larger sample size using meta-analysis. The expression level of miR-452-5p in LUSC was confirmed using a total of 720 samples from TCGA and GEO, and whilst He et al (29) detected miR-452-5p expression in 76 LUSC samples, no association between high miR-452-5p expression and LUSC was observed. Secondly, the clinical value of miR-452-5p as a biomarker was considered in the present study, where it is indicated that miR-452-5p may 
Table IV. Relative expression of 5 hub target genes of miR-452-5p in LUSC analyzed using data from The Cancer Genome Atlas.

\begin{tabular}{|c|c|c|c|c|}
\hline \multirow[b]{2}{*}{ Groups } & \multirow[b]{2}{*}{$\mathrm{n}$} & \multicolumn{3}{|c|}{ Hub gene relevant expression $\left(\log _{2}\right)$} \\
\hline & & Mean \pm SD & $\mathrm{z}$ & P-value \\
\hline \multicolumn{5}{|l|}{ CDKN1B } \\
\hline Non-cancer & 52 & $10.4490 \pm 0.47049$ & -2.277 & $0.023^{\mathrm{a}}$ \\
\hline LUSC & 511 & $10.3141 \pm 0.60619$ & & \\
\hline \multicolumn{5}{|l|}{ SMAD2 } \\
\hline Non-cancer & 52 & $10.8716 \pm 0.18524$ & -1.076 & 0.282 \\
\hline LUSC & 511 & $10.9439 \pm 0.54278$ & & \\
\hline \multicolumn{5}{|l|}{ SMAD4 } \\
\hline Non-cancer & 52 & $10.8014 \pm 0.22412$ & -5.275 & $<0.001^{\mathrm{a}}$ \\
\hline LUSC & 511 & $10.4572 \pm 0.55275$ & & \\
\hline \multicolumn{5}{|l|}{ YWHAB } \\
\hline Non-cancer & 52 & $12.8296 \pm 0.16600$ & -0.259 & 0.796 \\
\hline LUSC & 511 & $12.8083 \pm 0.40408$ & & \\
\hline \multicolumn{5}{|l|}{ YWHAE } \\
\hline Non-cancer & 52 & $13.1903 \pm 0.25322$ & -3.541 & $<0.001^{\mathrm{a}}$ \\
\hline LUSC & 511 & $13.4415 \pm 0.52233$ & & \\
\hline
\end{tabular}

${ }^{\mathrm{a}} \mathrm{P}<0.05$ vs. non-cancerous tissue. LUSC, lung squamous cell carcinoma; $\mathrm{SD}$, standard deviation; CDKN1B, cyclin dependent kinase inhibitor 1B; YWHAB, tyrosine 3-monooxygenase/tryptophan 5-monooxygenase activation protein $\beta$; YWHAE, tyrosine 3-monooxygenase/tryptophan 5-monooxygenase activation protein $\varepsilon$.

contribute to the diagnosis of LUSC. Furthermore, miR-452-5p may be useful in predicting the progression of LUSC due to the close association between miR-452-5p expression and TNM stage. Finally, a systematic analysis of the potential molecular mechanisms of miR-452-5p function in biological processes that underlie LUSC was performed. A combination of 14 online prediction tools were employed to screen target genes of miR-452-5p. As a result, $249 \mathrm{miR}-452-5 \mathrm{p}$ target genes were selected for GO and pathway analyses, it was indicated that the target genes primarily functioned by binding with protein, chromatin or other biological molecules, which are involved in transcriptional regulation.

Additionally, in order to analyze the key protein involved in the carcinogenesis, protein-protein interaction (PPI) analysis of 249 miR-452-5p target genes was applied. Consequently, 10 hub genes including SMAD4, SMAD2, CDKN1B, YWHAB, YWHAE, MEF2C, SMARCA4, PAFAH1B1, PRKAR2B and RPA1 were identified for additional study. Of these, the hub genes involved in cell cycle, including SMAD4, SMAD2, CDKN1B, YWHAE and YWHAB, are of particular interest. The cell cycle is a critical pathway that is closely associated with the prognosis and therapy of numerous malignancies, particularly LUSC $(38,39)$. In addition, half of the 10 hub genes were significantly enriched in 'cell cycle'. Notably, CDKN1B has been reported to function as a tumor suppressor gene in hepatocellular carcinoma and it is targeted by miR-452-5p (23). Therefore, it was hypothesized if
CDKN1B, a hub gene which is involved in cell cycle, may have an important role in molecular targeting therapy of LUSC. In the present study, it was demonstrated that the expression of miR-452-5p was negatively associated with the levels of CDKN1B in LUSC and this association was not statistical significant in normal lung tissues. These findings provide a direction for future investigation of the molecular mechanism that underlies miR-452-5p function in LUSC. Consistent with the results in the present study, Zheng et al (23) reported that miR-452-5p may directly target and suppress the expression of CDKN1B in hepatocellular carcinoma (23). The study also indicated that miR-452-5p may have a role in LUSC. Further experimental studies that investigate the association between CDKN1B and miR-452-5p will help to elucidate the mechanisms that underlie the carcinogenesis of LUSC.

However, several limitations exist in the present study. Firstly, heterogeneity may inevitably be present in the meta-analysis of 720 samples, resulting from numerous factors, including the detection method used, region, sex, age, stage and the type of LUSC specimens (fresh frozen tissue, formalin-fixed paraffin-embedded tissue or peripheral blood specimens). Therefore, future evidence-based confirmation and subgroup analyses by large-scale clinical trials are required to investigate the source of the heterogeneity. Secondly, miRNAs regulate the function of target genes during carcinogenesis and cancer progression through different biological pathways, which form a complex regulatory network of interactions involving biological molecules. Therefore, the present study utilized bioinformatic methods to predict the rudimentary function and mechanism of target genes. GO and pathway analyses were conducted and a PPI network model of biological molecules was constructed. However, in order to determine the mechanisms of miR-452-5p involved in LUSC, further verification, through in vitro and in vivo experiments as well as clinical trials, is required to identify new targets for potential treatments of LUSC patients.

In summary, relatively high levels of miR-452-5p expression in LUSC compared with non-cancerous lung tissues were determined by meta-analysis, which utilized experimental data obtained from TCGA and GEO. In addition, high expression of miR-452-5p was closely associated with the clinical parameters of LUSC, including age, cancer location and TNM stage. Furthermore, it is speculated that miR-452-5p serves a critical role in LUSC carcinogenesis by targeting CDKN1B, which is involved in cell cycle. Taken together, these findings provide a new direction for the development of tools for early diagnosis and targeted treatment of LUSC.

\section{Acknowledgements}

Not applicable.

\section{Funding}

The present study was supported by a fund from the Guangxi Provincial Health Bureau Scientific Research Project (grant nos. Z2013201 and Z2014055), the National Natural Science Foundation of China (grant nos. NSFC81360327 and NSFC81560469), the Natural Science Foundation of Guangxi, China (grant no. 2015GXNSFCA139009), the Scientific Research Project of the Guangxi Education Agency (grant 
nos. KY2015 and LX062) and the Scientific Research Project of the Basic Ability Promoting for Middle Age and Youth Teachers of Guangxi Universities (grant no. KY2016YB077).

\section{Availability of data and materials}

All data generated or analyzed during this study are included in this published article

\section{Authors' contributions}

XG, TG, RH, JL, RT, HW, HZ, JM and HQ performed the literature search, data extraction and statistical analysis, and drafted the paper. GC and XH supervised the literature search, data extraction and analysis, and reviewed the paper. All authors have read and approved the manuscript.

\section{Ethics approval and consent to participate}

The study protocol was approved by the Ethics Committee of the First Affiliated Hospital of Guangxi Medical University, with informed consent signed by all participants.

\section{Consent for publication}

Not applicable.

\section{Competing interests}

The authors declare that they have no competing interests.

\section{References}

1. Chen W, Zheng R, Baade PD, Zhang S, Zeng H, Bray F, Jemal A Yu XQ and He J: Cancer statistics in China, 2015. CA Cancer J Clin 66: 115-132, 2016.

2. McGuire S: World cancer report 2014. Geneva, Switzerland: World health organization, international agency for research on cancer, WHO Press, 2015. Adv Nutr 7: 418-419, 2016.

3. $\mathrm{Hu} \mathrm{M}, \mathrm{Hu} \mathrm{Y}, \mathrm{He} \mathrm{J}$ and $\mathrm{Li} \mathrm{B}$ : Prognostic value of basic fibroblast growth factor (bFGF) in lung cancer: A systematic review with meta-analysis. PLoS One 11: e0147374, 2016.

4. Schmidt B, Beyer J, Dietrich D, Bork I, Liebenberg V and Fleischhacker M: Quantification of cell-free mSHOX2 Plasma DNA for therapy monitoring in advanced stage non-small cell (NSCLC) and small-cell lung cancer (SCLC) patients. PLoS One 10: e0118195, 2015

5. Takahashi A, Ishii G, Neri S, Yoshida T, Hashimoto H, Suzuki S, Umemura S, Matsumoto S, Yoh K, Niho S, et al: Podoplanin-expressing cancer-associated fibroblasts inhibit small cell lung cancer growth. Oncotarget 6: 9531-9541, 2015.

6. Meza R, Meernik C, Jeon J and Cote ML: Lung cancer incidence trends by gender, race and histology in the United States, 1973-2010. PLoS One 10: e0121323, 2015.

7. Sun Y, Han Y, Wang X, Wang W, Wang X, Wen M, Xia J, Xing H, Li X and Zhang Z: Correlation of EGFR Del 19 with Fn14/JAK/STAT signaling molecules in non-small cell lung cancer. Oncol Rep 36: 1030-1040, 2016.

8. Lee CK, Brown C, Gralla RJ, Hirsh V, Thongprasert S, Tsai CM, Tan EH, Ho JC, Chu da T, Zaatar A, et al: Impact of EGFR inhibitor in non-small cell lung cancer on progression-free and overal survival: A meta-analysis. J Natl Cancer Inst 105: 595-605, 2013

9. Drilon A, Rekhtman N, Ladanyi M and Paik P: Squamous-cell carcinomas of the lung: Emerging biology, controversies, and the promise of targeted therapy. Lancet Oncol 13: e418-e426, 2012.

10. Xu C, Li S, Chen T, Hu H, Ding C, Xu Z, Chen J, Liu Z, Lei Z, Zhang HT, et al: miR-296-5p suppresses cell viability by directly targeting PLK1 in non-small cell lung cancer. Oncol Rep 35: 497-503, 2016.
11. Liu Y, Miao L, Ni R, Zhang H, Li L, Wang X, Li X and Wang J: microRNA-520a-3p inhibits proliferation and cancer stem cell phenotype by targeting HOXD8 in non-small cell lung cancer. Oncol Rep 36: 3529-3535, 2016.

12. Wang D, Ma J, Ji X, Xu F and Wei Y: miR-141 regulation of EIF4E expression affects docetaxel chemoresistance of non-small cell lung cancer. Oncol Rep 37: 608-616, 2017.

13. Zhou L, Di Q, Sun B, Wang X, Li M and Shi J: MicroRNA-194 restrains the cell progression of non-small cell lung cancer by targeting human nuclear distribution protein C. Oncol Rep 35: 3435-3444, 2016.

14. Chen X, Wei L and Zhao S: miR-338 inhibits the metastasis of lung cancer by targeting integrin 33 . Oncol Rep 36: 1467-1474, 2016.

15. Wu X, Liu T, Fang O, Dong W, Zhang F, Leach L, Hu X and Luo Z: MicroRNA-708-5p acts as a therapeutic agent against metastatic lung cancer. Oncotarget 7: 2417-2432, 2016.

16. Li D, Du X, Liu A and Li P: Suppression of nucleosome-binding protein 1 by miR-326 impedes cell proliferation and invasion in non-small cell lung cancer cells. Oncol Rep 35: 1117-1124, 2016.

17. Taylor MA, Wappett M, Delpuech O, Brown H and Chresta CM: Enhanced MAPK signaling drives ETS1-mediated induction of miR-29b leading to downregulation of TET1 and changes in epigenetic modifications in a subset of lung SCC. Oncogene 35: 4345-4357, 2016.

18. Olbromski M,GrzegrzolkaJ,Jankowska-Konsur A, Witkiewicz W, Podhorska-Okolow M and Dziegiel P: MicroRNAs modulate the expression of the SOX18 transcript in lung squamous cell carcinoma. Oncol Rep 36: 2884-2892, 2016.

19. Altuvia Y, Landgraf P, Lithwick G, Elefant N, Pfeffer S, Aravin A, Brownstein MJ, Tuschl T and Margalit H: Clustering and conservation patterns of human microRNAs. Nucleic Acids Res 33: 2697-2706, 2005

20. Bentwich I, Avniel A, Karov Y, Aharonov R, Gilad S, Barad O, Barzilai A, Einat P, Einav U, Meiri E, et al: Identification of hundreds of conserved and nonconserved human microRNAs. Nat Genet 37: 766-770, 2005.

21. Veerla S, Lindgren D, Kvist A, Frigyesi A, Staaf J, Persson H, Liedberg F, Chebil G, Gudjonsson S, Borg A, et al: MiRNA expression in urothelial carcinomas: Important roles of miR-10a, miR-222, miR-125b, miR-7 and miR-452 for tumor stage and metastasis, and frequent homozygous losses of miR-31. Int $\mathrm{J}$ Cancer 124: 2236-2242, 2009.

22. Liu SG, Qin XG, Zhao BS, Qi B, Yao WJ, Wang TY, Li HC and Wu XN: Differential expression of miRNAs in esophageal cancer tissue. Oncol Lett 5: 1639-1642, 2013.

23. Zheng Q, Sheng Q, Jiang C, Shu J, Chen J, Nie Z, Lv Z and Zhang Y: MicroRNA-452 promotes tumorigenesis in hepatocellular carcinoma by targeting cyclin-dependent kinase inhibitor 1B. Mol Cell Biochem 389: 187-195, 2014.

24. Hu Q, Gong JP, Li J, Zhong SL, Chen WX, Zhang JY, Ma TF, Ji H, Lv MM, Zhao JH and Tang JH: Down-regulation of miRNA-452 is associated with adriamycin-resistance in breast cancer cells. Asian Pac J Cancer Prev 15: 5137-5142, 2014

25. Kristensen H,Haldrup C, Strand S, Mundbjerg K, Mortensen MM, Thorsen K, Ostenfeld MS, Wild PJ, Arsov C, Goering W, et al: Hypermethylation of the GABRE miR-452 miR-224 promoter in prostate cancer predicts biochemical recurrence after radical prostatectomy. Clin Cancer Res 20: 2169-2181, 2014.

26. Liu L, Chen K, Wu J, Shi L, Hu B, Cheng S, Li M and Song L: Downregulation of miR-452 promotes stem-like traits and tumorigenicity of gliomas. Clin Cancer Res 19: 3429-3438, 2013.

27. Zhang Y, Han L, Pang J, Wang Y, Feng F and Jiang Q: Expression of microRNA-452 via adenoviral vector inhibits non-small cell lung cancer cells proliferation and metastasis. Tumour Biol 37: 8259-8270, 2016

28. He Z, Xia Y, Pan C, Ma T, Liu B, Wang J, Chen L and Chen Y: Up-regulation of MiR-452 inhibits metastasis of non-small cell lung cancer by regulating BMI1. Cell Physiol Biochem 37: 387-398, 2015.

29. He Z, Xia Y, Liu B, Qi X, Li Z, Wang J, Chen L and Chen Y: Down-regulation of miR-452 is associated with poor prognosis in the non-small-cell lung cancer. J Thorac Dis 8: 894-900, 2016.

30. Merico D, Isserlin R, Stueker O, Emili A and Bader GD: Enrichment map: A network-based method for gene-set enrichment visualization and interpretation. PLoS One 5: e13984, 2010.

31. Shannon P, Markiel A, Ozier O, Baliga NS, Wang JT, Ramage D, Amin N, Schwikowski B and Ideker T: Cytoscape: A software environment for integrated models of biomolecular interaction networks. Genome Res 13: 2498-2504, 2003. 
32. Shannon PT, Grimes M, Kutlu B, Bot JJ and Galas DJ: RCytoscape: Tools for exploratory network analysis. BMC Bioinformatics 14: 217, 2013.

33. Beckers A, Van Peer G, Carter DR, Mets E, Althoff K, Cheung BB, Schulte JH, Mestdagh P, Vandesompele J, Marshall GM, et al: MYCN-targeting miRNAs are predominantly downregulated during MYCN-driven neuroblastoma tumor formation. Oncotarget 6: 5204-5216, 2015.

34. Wang J, Chu ES, Chen HY, Man K, Go MY, Huang XR, Lan HY, Sung JJ and Yu J: microRNA-29b prevents liver fibrosis by attenuating hepatic stellate cell activation and inducing apoptosis through targeting PI3K/AKT pathway. Oncotarget 6: 7325-7338, 2015.

35. Zou ZJ, Fan L, Wang L, Xu J, Zhang R, Tian T, Li JY and Xu W: miR-26a and miR-214 down-regulate expression of the PTEN gene in chronic lymphocytic leukemia, but not PTEN mutation or promoter methylation. Oncotarget 6: 1276-1285, 2015.

36. Li J, Guan J, Long X, Wang Y and Xiang X: mir-1-mediated paracrine effect of cancer-associated fibroblasts on lung cancer cell proliferation and chemoresistance. Oncol Rep 35: 3523-3531, 2016.
37. Peng J, Liu HZ, Zhong J, Deng ZF, Tie CR, Rao Q, Xu W, You T, Li J, Cai CB, et al: MicroRNA-187 is an independent prognostic factor in lung cancer and promotes lung cancer cell invasion via targeting of PTRF. Oncol Rep 36: 2609-2618, 2016.

38. Fukazawa T, Guo M, Ishida N, Yamatsuji T, Takaoka M, Yokota E, Haisa M, Miyake N, Ikeda T, Okui T, et al: SOX2 suppresses CDKN1A to sustain growth of lung squamous cell carcinoma. Sci Rep 6: 20113, 2016

39. Cannell IG, Merrick KA, Morandell S, Zhu CQ, Braun CJ, Grant RA, Cameron ER, Tsao MS, Hemann MT and Yaffe MB: A pleiotropic RNA-binding protein controls distinct cell cycle checkpoints to drive resistance of p53-defective tumors to chemotherapy. Cancer Cell 28: 623-637, 2015.

This work is licensed under a Creative Commons Attribution-NonCommercial-NoDerivatives 4.0 International (CC BY-NC-ND 4.0) License. 